\title{
[第19回日本レーザー医学会大会報告］ 〈教育講演〉
}

ENDOSCOPIC DIAGNOSIS OF SWALLOWING DISTURBANCE

\author{
Jonathan E. Aviv, MD, FACS \\ Department of Otolaryngology-Head and Neck Surgery \\ The New York Presbyterian Hospital \\ College of Physicians and Surgeons \\ Columbia University, New York, USA
}

This work is supported by National Institutes of Health grant RR 00645 and the ColumbiaPresbyterian Medical Center Office of Clinical Trials.

Presented at the $19^{\text {th }}$ Congress of Japanese Society for Laser Surgery and Medicine September 25, 1998 Tokyo, Japan

Reprints: Jonathan E. Aviv, MD, FACS

Director, Division of Head and Neck Surgery

Box 21, Dept. of Otolaryngology-Head and Neck Surgery

Columbia-Presbyterian Medical Center

630 West $168^{\text {th }}$ Street

New York, New York 10032

(212) 305-1602 FAX (212) 305-3975

\begin{abstract}
Objective: To introduce an office or bedside method of evaluating both the motor and sensory components of swallowing called Flexible Endoscopic Evaluation of Swallowing with Sensory Testing (FEESST). FEESST combines the established endoscopic evaluation of swallowing
\end{abstract}


with a technique that determines laryngopharyngeal sensory discrimination thresholds by endoscopically delivering air pulse stimuli to the mucosa innervated by the superior laryngeal nerve.

Methods: Endoscopic assessment of laryngopharyngeal sensory capacity followed by endoscopic visualization of deglutition was prospectively performed 148 times on 133 patients with dysphagia over an 8 month period. The patients had a variety of underlying diagnoses, with stroke and chronic neurological disease predominating $(n=94)$. Subsequent to sensory testing, a complete dysphagia evaluation was conducted. Various food and liquid consistencies were dyed green and attention was paid to their management throughout the pharyngeal stage of swallowing. Evidence of latent swallow initiation, pharyngeal pooling and / or residue, laryngeal penetration, laryngeal aspiration and / or reflux was noted. Recommendations for therapeutic intervention were based upon information obtained during the FEESST and involved dietary and behavioral modifications, prevention of oral alimentation and/or referral to other related specialists.

Results: All patients successfully completed the examination. In 111 of the evaluations (75\%), severe ( $>6.0 \mathrm{~mm} \mathrm{Hg}$ air pulse pressure) unilateral or bilateral LP sensory deficits were found. With puree consistencies, $47 \%$ of evaluations with severe deficits compared to $11 \%$ of evaluations with either normal sensitivity or moderate $(4.0-6.0 \mathrm{~mm} \mathrm{Hg}$ air pulse pressure ) sensory deficits displayed aspiration $(\mathrm{p}<.001$, chi-squared test). With puree consistencies, $69 \%$ of evaluations with severe deficits compared to $24 \%$ with normal or moderate deficits displayed laryngeal penetration $(p<.001$, chi-squared test).

Conclusion: FEESST allows the clinician to obtain a comprehensive sensorimotor assessment of swallowing that is performed as the initial swallowing evaluation for the patient with dysphagia. 


\section{INTRODUCTION}

Pneumonia, particularly aspiration pneumonia, is a cause of tremendous morbidity and mortality in both the nursing home and hospital settings $(1,2,3)$. While the etiology of aspiration pneumonia is multifactorial, numerous studies have shown a significant association between dysphagia, or difficulty swallowing, and development of aspiration pneumonia (4-8). The theory supported by these studies is that dysphagia leads to aspiration of food and secretions which, ultimately, results in development of pneumonia. To control the problem of aspiration pneumonia, clinicians guide the behavioral and dietary management of their patients with dysphagia with a traditional bedside swallowing evaluation. It is well described in the literature that a bedside evaluation alone is not a very accurate method of guiding management of patients with dysphagia (9-11). Both modified barium swallow (MBS) (or videofluoroscopy) and fiberoptic endoscopic examination of swallowing (FEES) are well known to be far more accurate in describing and analyzing swallowing disorders and guiding behavioral and dietary management (12-15).

It is impractical and expensive to perform a MBS in certain settings, such as the clinicians office, the nursing home, the patients home and the intensive care unit. FEES, on the other hand, is ideally suited for such settings in that it can be performed at the bedside, and it gives essentially the same information as the MBS, in particular with regards to reliably identifying those who aspirate $(12,13,16,17)$. Furthermore, FEES is half the cost of a MBS.

One of the shortcomings of FEES and MBS is that they primarily analyze the motor component of swallowing, but only indirectly the sensory component. Unrecognized, or insufficiently recognized, sensory deficits in the laryngopharynx can lead to dysphagia and aspiration, the theory being that if one can not sense food and secretions in the laryngopharynx, normal laryngopharyngeal protective reflexes will not be properly initiated, resulting in secretions and debris descending into both the esophagus and into the tracheo- 
bronchial tree $(18-22)$. Until recently, a reliable sensory assessment of the pharynx and larynx had not been available to be used in conjunction with FEES. However, over the past several years a simple, reliable method of laryngopharyngeal sensory discrimination testing that is performed at the same time, and with essentially the same equipment, as a traditional FEES exam, has been developed $(23,24)$. Since endoscopy (FEES) can give essentially the same information as fluoroscopy (MBS) $(13,17,25)$, the combination of sensory testing with FEES to form flexible endoscopic evaluation of swallowing with sensory testing (FEESST) gives one the capability of providing a comprehensive, bedside, motor and sensory assessment of swallowing (26). FEESST has previously been shown to be a reliable method of evaluating deglutition in healthy controls (26). The purpose of this study is to demonstrate the application of FEESST in the evaluation of patients with dysphagia.

\section{MATERIALS AND METHODS}

FEESST was prospectively performed 148 times in 133 patients with dysphagia over an 8 month period from January through August 1996. The selection criteria for inclusion in the study were as follows: In-patients and outpatients at the ColumbiaPresbyterian Medical Center referred for an endoscopic swallowing evaluation by their attending physician because of a patient complaint of dysphagia. Dysphagia was defined as any subjective or objective patient complaint of difficulty swallowing solid or liquid food, or the presence of coughing or choking while swallowing. Informed consent was obtained on all subjects in the study. The patients had a variety of underlying diagnoses and conditions, including stroke, chronic neurological disease (Parkinson's disease, amyotrophic lateral sclerosis, multiple sclerosis), bronchiectasis, pneumonia, dementia, dysphagia after open heart surgery and dysphagia after prolonged intubation. Stroke and chronic neurological disease predominated $(n=94)$. 


\section{FEESST PROTOCOL}

The equipment necessary to perform an office or bedside endoscopic swallowing evaluation with sensory testing included an endoscope, a light source, a sensory stimulator that attaches to the endoscope, a television monitor, a lapel microphone, a mavigraph and a video-cassette-recorder.

Prior to passing the endoscope a history was obtained and a physical examination of the head and neck was performed. Subsequently, the endoscope was placed. Prior to performing laryngopharyngeal sensory testing and prior to administration of food the following was assessed, as described by Langmore (12) and Bastian (27): velopharyngeal closure, anatomy of base of tongue and hypopharynx, abduction and adduction of the vocal folds, status of pharyngeal musculature and the patients ability to handle and swallow their saliva and their secretions.

Once these observational tasks were completed, and prior to administration of solid and liquid food, sensory testing formally took place by administration of pulses of air to the aryepiglottic folds. All data was recorded on sensory testing and FEESST forms (Figures 1 and 2).

Laryngopharyngeal sensory discrimination thresholds were determined by using air pulse stimulation of the mucosa innervated by the superior laryngeal nerve (SLN) in order to elicit the laryngeal adductor reflex $(\operatorname{LAR})(19,28)$. Stimulation of the mucosa innervated by the SLN elicits the LAR, which is a brief closure of the true vocal folds $(29,30)$. The advantage of eliciting the LAR is that it is an involuntary reflex $(31,32)$, thereby allowing testing of patients with cognitive deficits.

\section{LARYNGOPHARYNGEAL SENSORY DISCRIMINATION TESTING}

\section{Stimulus Delivery}

To measure the supraglottic and pharyngeal sensory level, a pressure and duration controlled pulse of air was delivered either to the anterior wall of the pyriform sinus or to the 
Figure 1.

\section{LARYNGOPHARYNGEAL SENSORY DISCRIMINATION TESTING (LPSDT) FORM}

Medical Record Number:

Date of interview: (mmddyy)

LPSDT

+: Positive response -: Negative response LC: Laryngeal Closure S:Swallow DATA ( $\mathrm{mm} \mathrm{Hg})$

RIGHT

\section{LEFT}

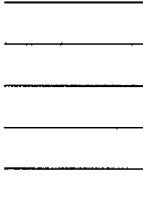

Threshold:

Threshold:

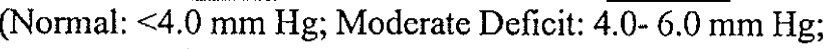

Severe Deficit: $>6.0 \mathrm{~mm} \mathrm{Hg}$ )

Laryngopharyngeal sensation:

$(0=$ normal $1=$ moderate deficit $2=$ severe deficit $)$

Right: _ Left:

\section{SAFETY}

Airway Compromise:

Epistaxis:

$0=$ No $\quad 1=$ Yes

$0=\mathrm{No} \quad 1=\mathrm{Yes}$

Patient Discomfort:

$0=$ None $1=$ Mild $2=$ Moderate $3=$ Severe

If your physician advised that you repeat this test, would you repeat this test:

$0=$ No $1=$ Yes

aryepiglottic folds (the area innervated by the SLN). The air pulse, $50 \mathrm{msec}$ in duration, was varied in intensity from $0 \mathrm{~mm} \mathrm{Hg}$ to $10 \mathrm{~mm} \mathrm{Hg}$. It was delivered via an internal port located within a flexible fiberoptic telescope made for this purpose (Pentax Precision Instrument Corporation, Orangeburg, New York, USA). The air pulse was obtained from a laryngopharyngeal air pulse sensory stimulator developed for this purpose (Pentax Precision Instrument Corporation, Orangeburg, New York, USA). The flexible laryngoscope was inserted into the nasal passage, and the distal tip of the scope was advanced, under direct vision, until it was located approximately $2 \mathrm{~mm}$ from the test site. No topical anesthesia was utilized. The patient was then given a 1 minute rest period to adapt to the laryngoscope and prepare for testing. 
Figure 2. FIBEROPTIC ENDOSCOPIC EVALUATION of SWALLOWING with SENSORY TESTING (FEESST)

Date of exam: (mmddyy) Sex: $0=\mathrm{F} 1=\mathrm{M}$; Date of Birth: $(\mathrm{mm} / \mathrm{dd} / \mathrm{yy})$

Race/Ethnicity: _ $\quad(0=$ White, $\mathrm{NH} 1=\mathrm{B}$ lack, NH, $2=$ Hispanic $3=$ Other $)$

Diagnosis: $1=$ stroke $2=$ dementia $3=$ heart attack $4=$-pneumonia $5=$ cancer $6=$ other

\section{DIET HISTORY}

Current weight: (lbs.)

Weight loss in past 3 months: _ $0=$ No $1=Y$ Yes

Current Diet:NPO: _ NGT: $\quad$ PEG: $\quad(0=$ No $1=$ Yes $)$

Liquid: _ _ $(0=$ honey $1=$ nectar $2=$ thin $3=$ none $)$

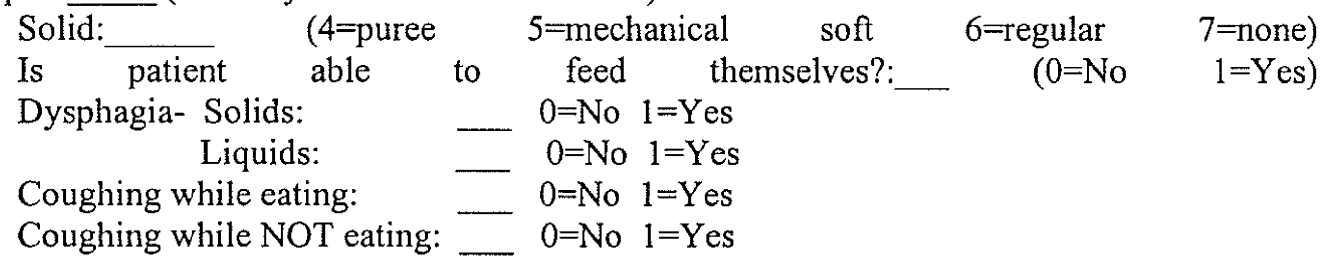

\section{PHYSICAL EXAM}

Alert: $\quad 0=$ No $1=$ Yes

Functional communication: __ $\quad 1=$ intact $2=$ impaired $3=$ absent

Lips: $\quad 0=$ normal $1=$ asymmetric

(For the following enter: $1=$ intact $2=$ impaired $3=$ absent)

Tongue movement:

Tongue strength:

Soft palate movement:

Gag:

Volitional cough:

Volitional swallow:

Spontaneous swallow:

Laryngeal elevation:

Voice quality: $0=\overline{\text { Normal }} 1=$ hoarse $2=$ wet

\section{SWALLOWING EVALUATION}

Testing position: $0=$ Chair, upright; $1=$ Chair, 45 degrees; $2=$ Bed, upright; $3=$ Bed, 45 degrees Pre test heart rate: (mm Hg) (Beats per minute) Pre test blood pressure:

ENDOSCOPIC EXAM

Vocal cord adduction- Complete: $(0=$ No $\quad 1=$ Yes $)$ Able to breath hold for 1 second: Incomplete: Able to breath hold for 5 seconds:

Laryngopharyngeal sensation: ( $0=$ normal $1=$ moderate deficit $2=$ severe deficit $)$ Right: Left:

\section{Laryngeal Adductor Reflex}

The fiberoptic telescope was inserted into the nose and 3 blocks of ascending and 3 blocks of descending air pulse stimulus presentations were given, noting at what stimulation pressure transient vocal fold closure took place. Within a block, air pulses were presented in sequential steps of $1.0 \mathrm{~mm} \mathrm{Hg}$; from subliminal to supraliminal for ascending blocks and from supraliminal to subliminal for descending blocks. A 30 second rest period separated 
Figure 2. FEESST FORM (Continued)

\begin{tabular}{|c|c|c|c|c|c|c|}
\hline $\begin{aligned} \text { Enter } 0 & =\text { No } \\
1 & =\text { Yes }\end{aligned}$ & $\begin{array}{l}\text { ICE } \\
\text { CHIPS }\end{array}$ & PUREE & NECTAR & HONEY & THIN & $\begin{array}{l}\text { MECH } \\
\text { SOFT }\end{array}$ \\
\hline \multicolumn{7}{|l|}{ SPILLAGE* } \\
\hline $\begin{array}{l}\text { LARYNGEAL } \\
\text { PENETRATION } \\
\text { Able to clear }\end{array}$ & & & & & & $\bar{\square}$ \\
\hline $\begin{array}{l}\text { PHARYNGEAL } \\
\text { RESIDUE/POOLING } \\
\text { Able to clear }\end{array}$ & - & & & {[} & & \\
\hline $\begin{array}{l}\text { ASPIRATION } \\
\text { response: } \\
\text { - Silent } \\
\text { - Cough } \\
\text { Able to clear }\end{array}$ & & {$\left[\begin{array}{l}\square \\
\square\end{array}\right.$} & $\bar{T}$ & {$\left[\begin{array}{l}\square \\
\square\end{array}\right.$} & 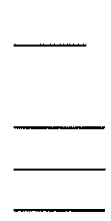 & \\
\hline $\begin{array}{l}\text { REFLUX } \\
\text { Able to clear }\end{array}$ & 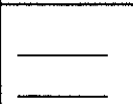 & & 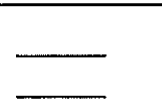 & - & $\bar{Z}$ & 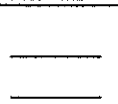 \\
\hline
\end{tabular}

* - Head of bolus into hypopharynx $>1$ second before swallowing response occurs

BEHAVIORAL MODIFICATIONS: $(0=$ No $1=$ Yes)

Postural changes: __ Other measures (eg., throat clear, small bites/sips, etc):

INCREASED RISK OF ASPIRATION DUE TO: $\quad(0=$ No $1=$ Yes $)$

Poor oral control and copious oral residue:

Diminished laryngopharyngeal sensation:

Premature spillage of bolus:

Inability to clear material from vallecula, pharynx, pyriforms or endolarynx:

Reflux:

Post test heart rate:

IMPRESSION:

(Beats per minute) Blood pressure: $\overline{(\mathrm{mm} H g})$

\section{RECOMMENDATION:}

Referrals: $(0=$ No $1=$ Yes): SLP(Dysphagia Therapy) ENT:

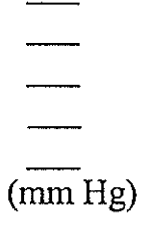

DIET: $(0=$ No $1=$ Yes) NPO: NGT: PEG

Liquid: $(0=$ honey $1=$ nectar $2=$ thin $3=$ none $)$

Solid: _ ( $\quad$ (4=puree $5=$ mechanical soft $6=$-regular $7=$ none)

Position:__ ( $(0=$ Chair, upright; $1=$ Chair, 45 degrees; $2=$ Bed, upright; $3=\mathrm{Bed}, 45$ degrees $)$

BEHAVIORAL MODIFICATIONS: ( $0=$ No $1=\mathrm{Yes})$

Postural changes: Other measures (eg., throat clear, small bites/sips, etc):

Supervision: $(0=$ none necessary $1=$ intermittent $2=$ constant $)$

the blocks.

Transient vocal fold closure was determined by direct visualization of vocal fold movement on a video monitor receiving a real time image from the fiberoptic telescope. When the reflex is absent, the vocal folds fail to close after stimulation in this region. The type of vocal fold closure taking place in response to air pulse stimulation was a brief, rapid, non-rhythmic vocal fold adduction thus clearly distinguishable from the rhythmic vocal fold movement seen during normal respiration (29-32). The mean of the lowest pressures from 
the 6 blocks that elicited brief laryngeal adduction were recorded as that subject's threshold. Both the right and left sides of the pharynx and supraglottic larynx were studied.

\section{Swallowing Evaluation}

Subsequent to laryngopharyngeal sensory testing, a complete dysphagia evaluation was conducted. Prior to the administration of food trials, attention was paid to the management of secretions and evidence of copious secretions being pooled, penetrated or aspirated was noted. Following the collection of baseline information, various food and liquid consistencies were dyed green and attention was paid to their management throughout the pharyngeal stage of swallowing. Evidence of latent swallow initiation, pharyngeal pooling and/or residue, laryngeal penetration, laryngeal aspiration and/or reflux was noted. Spillage is defined as a food bolus coursing into the hypopharynx more than one second before a swallowing response occurs. Pharyngeal residue is defined as persistence of green colored material along the pharyngeal walls or within the pyriform sinuses or valleculae. Laryngeal penetration is defined as passage of material into the larynx that does not pass below the vocal folds. Aspiration is defined as passage of material below the level of the true vocal folds. Reflux is defined as passage of material from the esophageal inlet retrograde into the laryngopharynx before, during or after the swallow.

Food and liquid consistencies were presented in the following sequence: pureed food, thickened liquid, mechanical soft food, thin liquid and regular food. Manipulation of the bolus size was generally conducted by initially presenting a quarter teaspoon, followed by a half teaspoon and concluding with full teaspoon trials. Similarly, liquids were presented by spoon, cup, and finally by straw. In addition, the patient was presented with at least 3 repeated trials of each consistency. In an effort to simulate a typical feeding experience, those patients capable of feeding themselves were asked to ad-lib self administration. Each swallowing evaluation lasted for approximately 20 to 30 minutes, 
further simulating a natural mealtime experience, and allowed the clinician to consider fatigue and its effect on swallowing function.

Various compensatory and swallowing treatment strategies were attempted throughout the FEESST in order to determine their efficacy for remediation purposes. Postural changes, which alter the pharyngeal dimensions or gravity's effect on bolus movement, included a chin tuck, head rotation, or a head tilt. Therapeutic swallow maneuvers were also employed to improve airway protection, increase laryngeal elevation, and increase pharyngeal peristalsis. These maneuvers included a supraglottic swallow, a super-supraglottic swallow, an effortful swallow, and a Mendelsohn Maneuver. In addition, food viscosity, temperature and oral presentation were manipulated to further compensate for sensory and motor dysfunction. By determining effective therapeutic techniques, we attempted to identify the intervention necessary to provide each patient with the safest swallow possible. Safety refers to a swallow which results in manageable amounts of pooling and residue, and the prevention of laryngeal penetration and aspiration.

The results of the sensory testing were combined with the results of the food administration trials to arrive at the dietary and therapeutic recommendations. For example, if a patient with a history of cortical stroke was found to have a contralateral laryngopharyngeal sensory deficit, a head turn towards the less sensitive side was performed in order to anatomically close the insensitive portion of the laryngopharynx, thereby exposing the incoming food bolus primarily to the sensate portion of the laryngopharynx. Another example is the patient with bilateral, severe sensory deficits and aspiration during the FEESST, who is not reacting to the aspirated material, i.e., the patient with silent aspiration and LP numbness. Such patients were managed with prevention of oral intake and alimentation by gastrostomy tube. In general, if a patient had bilateral sensory deficits, and aspirated pureed food and thick liquid, the remaining food consistencies were not attempted. 
also recorded on a FEESST form (Figure 2).

\section{STATISTICAL ANALYSIS}

A chi-squared test with one degree of freedom was used to assess differences in FEESST test results among each of the 5 food consistencies.

\section{RESULTS}

All patients successfully completed the examination with at least the puree consistency. 78 patients completed a course of purees, thick and thin consistencies and 48 patients were able to complete the endoscopic swallowing evaluation with all consistencies (puree, thick, thin, mechanical soft and regular). Sensory thresholds were defined as either normal ( $<4.0 \mathrm{~mm} \mathrm{Hg}$ air pulse pressure), moderate deficit (4.0-6.0 $\mathrm{mm} \mathrm{Hg}$ air pulse pressure) or severe deficits ( $>6.0 \mathrm{~mm} \mathrm{Hg}$ air pulse pressure) and recorded on a sensory testing form (Figure 1). In 111 of the evaluations (75\%), severe ( $>6.0 \mathrm{~mm} \mathrm{Hg}$ air pulse pressure) unilateral or bilateral sensory deficits were found. Because the majority of patients were tested with a puree consistency, the results of FEESST with puree will be presented in detail (Tables I and II).

For the puree consistency, $47 \%$ of evaluations with severe sensory deficits compared to $8 \%$ of evaluations with either normal sensitivity or moderate sensory deficits displayed aspiration ( $p<.001$, chi-squared test with one degree of freedom). $69 \%$ of evaluations with severe deficits compared to $8 \%$ with normal or moderate deficits displayed laryngeal penetration ( $p<.001$, chi-squared test with one degree of freedom). $65 \%$ of evaluations with severe deficits compared to $35 \%$ with normal or moderate deficits displayed pharyngeal residue ( $p<.001$, chi-squared test with one degree of freedom). $38 \%$ 
TABLE I. FEESST RESULTS: PUREE CONSISTENCY

\begin{tabular}{|l|c|c|c|c|c|}
\hline $\begin{array}{l}\text { LP } \\
\text { sensation }\end{array}$ & Spillage & Residue & $\begin{array}{l}\text { Laryngeal } \\
\text { Penetration }\end{array}$ & Aspiration & Reflux \\
\hline $\begin{array}{l}\text { Bilateral } \\
\text { severe } \\
(\mathrm{n}=71)\end{array}$ & 36 & 58 & 56 & 28 & 11 \\
\hline $\begin{array}{l}\text { Unilateral } \\
\text { severe } \\
(\mathrm{n}=40)\end{array}$ & 6 & 14 & 21 & 6 & 2 \\
\hline $\begin{array}{l}\text { TOTAL } \\
\text { (n=111) }\end{array}$ & 42 & 72 & 77 & 34 & 13 \\
$\begin{array}{l}\text { Bilateral } \\
\text { moderate } \\
\text { (n=7) }\end{array}$ & 1 & 4 & 0 & 1 & 1 \\
\hline $\begin{array}{l}\text { Moderate/ } \\
\text { normal } \\
(\mathrm{n}=9)\end{array}$ & 2 & 3 & 1 & 0 & 1 \\
\hline $\begin{array}{l}\text { Bilateral } \\
\text { normal } \\
(\mathrm{n}=21)\end{array}$ & 2 & 6 & 2 & 1 & 7 \\
\hline $\begin{array}{l}\text { TOTAL } \\
(\mathbf{n}=\mathbf{3 7})\end{array}$ & 5 & 13 & 3 & 2 & 9 \\
\hline
\end{tabular}

Legend

FEESST: Fiberoptic Endoscopic Evaluation of Swallowing with Sensory Testing LP: Laryngopharyngeal

TABLE II. FEESST RECOMMENDATIONS: PUREE CONSISTENCY

\begin{tabular}{|l|c|l|l|l|}
\hline $\begin{array}{l}\text { LP } \\
\text { sensation }\end{array}$ & UP GRADE & $\begin{array}{l}\text { DOWN } \\
\text { GRADE }\end{array}$ & NPO & PEG \\
\hline $\begin{array}{l}\text { Bilateral } \\
\text { severe } \\
(\mathrm{n}=71)\end{array}$ & 8 & 25 & 41 & 25 \\
\hline $\begin{array}{l}\text { Unilateral } \\
\text { severe } \\
(\mathrm{n}=40)\end{array}$ & 11 & 10 & 10 & 6 \\
\hline $\begin{array}{l}\text { TOTAL } \\
\text { (n=111) }\end{array}$ & 19 & 35 & 51 & 31 \\
\hline $\begin{array}{l}\text { Bilateral } \\
\text { moderate } \\
(\mathrm{n}=7)\end{array}$ & 1 & 1 & 2 & 1 \\
\hline $\begin{array}{l}\text { Moderate/ } \\
\text { normal } \\
(\mathrm{n}=9)\end{array}$ & 3 & 2 & 0 & 0 \\
\hline $\begin{array}{l}\text { Bilateral } \\
\text { normal } \\
(\mathrm{n}=21)\end{array}$ & 8 & 4 & 2 & 2 \\
\hline $\begin{array}{l}\text { TOTAL } \\
\text { (n=37) }\end{array}$ & 12 & 7 & 4 & 3 \\
\hline
\end{tabular}

Legend

FEESST: Fiberoptic Endoscopic Evaluation of Swallowing with Sensory Testing LP: Laryngopharyngeal

NPO: Nothing by mouth

PEG: Percutaneous Endoscopic Gastrostomy 
of evaluations with severe deficits compared to $14 \%$ with normal or moderate deficits displayed spillage $(p<.001$, chi-squared test with one degree of freedom). There was no significant difference between evaluations with severe deficits and those with normal or moderate deficits with respect to reflux ( $p>0.05$, chi-squared test with one degree of freedom).

FEESST recommendations were broadly divided into dietary and behavioral modifications. The dietary recommendations included diet upgrade, downgrade, nothing by mouth (NPO) and percutaneous endoscopic gastrostomy (PEG). Behavioral modifications included compensatory strategies such as postural changes, therapeutic swallow maneuvers, and manipulation of bolus viscosity, temperature, and oral presentation. These results are detailed in Table II. With respect to PEG and NPO the following was noted: $46 \%$ of evaluations with severe sensory deficits compared to $11 \%$ with normal or moderate deficits had a recommendation of NPO ( $\mathrm{p}<.001$, chi-squared test with one degree of freedom). $28 \%$ of evaluations with severe deficits compared to $8 \%$ with normal or moderate deficits had a recommendation of PEG $(\mathrm{p}<.001$, chi-squared test with one degree of freedom).

Fifteen evaluations demonstrated silent aspiration of the puree consistency, 13 of which had bilateral, severe sensory deficits. All those patients were made NPO and had a PEG placed. Recommendation of removal of PEG, as part of a diet upgrade, took place 9 times in this group of patients being evaluated for complaints of dysphagia.

\section{DISCUSSION}

The bedside clinical evaluation of patients with dysphagia misses roughly $60 \%$ of those patients who go on to aspirate on MBS (9). Assessment of the gag reflex is often used by physicians to assess swallowing function at the bedside (33). However, an abnormal gag reflex has been shown to be of quite limited prognostic value in predicting pneumonia $(14,21)$. The gag reflex measures afferent activity in the ninth cranial nerve, 
not the SLN branch of the tenth cranial nerve, which is the nerve that provides sensation to the hypopharynx and larynx $(34,35)$. Therefore, from an anatomic perspective, it is not surprising that assessment of the gag reflex fails to give reliable prognostic information regarding development of $\mathrm{AP}(4,20,36)$. In summary, the bedside swallowing evaluation is an inadequate examination because it not only fails to reliably detect aspiration, but it can not tell the examiner why a patient aspirated, therefore the examiner could not know what type of treatment to apply.

MBS and FEES are very useful for documenting the oropharyngeal swallowing sequence both in patients suspected of having dysphagia and in patients who have silent aspiration $(13-15,19,22)$. However, except for a single retrospective study (4), the MBS has not been shown to reliably predict who will develop aspiration pneumonia $(21,36$, 37).

Compared to endoscopic swallowing evaluations, there are 3 significant problems with MBS. One is that the MBS can not visualize accumulated secretions in the laryngopharynx. This is a critical shortcoming as studies have suggested that aspiration of accumulated secretions is a significant factor in the development of aspiration pneumonia $(16,38-40)$. The second problem with MBS is that due to the inherent temporal limitations of the examination, one generally misses patient fatigue. People typically do not complete a meal in 5 minutes, which is the maximum time of videofluoroscopy. The third problem with MBS is that it specifically visualizes the motor component of swallowing; only indirectly demonstrating the sensory component (21). A prospective study comparing MBS and sensory testing as predictors of pneumonia risk in stroke patients with dysphagia found that laryngopharyngeal sensory testing, when used in conjunction with MBS, decreased the false negative rate of MBS alone in predicting pneumonia from $40 \%$ to $0 \%(28)$.

In their original published descriptions of endoscopic swallowing evaluations, both Langmore, who introduced the term FEES (12), and Bastian, who introduced the 
term VEED (videoendoscopic evaluation of dysphagia) (27), recognized and addressed the need for, and importance of, sensitivity testing of the laryngopharynx as part of the endoscopic evaluation of swallowing. What they suggested was to lightly touch or tap the various tissues of the laryngopharynx with the tip of the endoscope and look for patient reaction. However, a clinical tap may be quite different from one examiner to another. In other words, touching the tissues of the laryngopharynx to assess sensitivity is not quantitative nor readily reproducible. Hence the development of sensory testing using air pulse stimulation of the mucosa overlying the SLN. Now, for the first time, one has the capability of providing a mobile, bedside, comprehensive sensorimotor assessment of swallowing.

A comprehensive, bedside test of swallowing, such as FEESST, is an important step in developing the ability to predict and to prevent aspiration pneumonia as such a diagnostic test can lead to more precise intervention in those with dysphagia. Our results indicate that patients with sensory deficits are more likely to demonstrate aspiration, laryngeal penetration, pharyngeal residue and spillage than those patients with no worse than a moderate sensory deficit. Our results suggest that the decision for a particular behavioral and dietary recommendation is a result of the coalescence of various forms of clinical information. The first tier of intervention is usually a modification of the patient's diet since certain food consistencies are less likely to be aspirated than others $(5,6)$. More complex intervention includes behavioral modifications such as compensatory strategies involving postural changes and therapeutic swallowing maneuvers, which could be quite accurately applied when using FEESST.

In this study, all patients with silent aspiration of the puree consistency and severe, bilateral sensory deficits were managed with prevention of oral intake and alimentation by gastrostomy tube. A recent prospective, randomized study has shown that stroke patients with severe dysphagia had a significantly lower incidence of aspiration pneumonia and death when managed with a PEG versus a naso-gastric tube 
Several studies have suggested that enteral feeding (PEG and nasogastric tube) offers no protection against the development of aspiration pneumonia (42-44). However, the basic problem with these studies is that the PEG was typically placed as a preterminal event. Once it is placed, all subsequent attention to oropharyngeal rehabilitation and re-establishment of oral intake ceases. The PEG is not used as a temporizing therapeutic maneuver because diagnostic tests thoroughly evaluating the swallow can not be readily obtained. In chronic care facilities in particular it is too expensive and cumbersome to transport patients with a PEG for an MBS. Traditionally, the only alternative to the MBS is the bedside evaluation, so one then necessarily relies on an inadequate examination to decide when the PEG feedings should be discontinued and oral feedings resumed. Endoscopic swallowing evaluations will necessarily bridge this information gap, so that the clinicians taking care of these patients can see how secretions, then food types, are handled during the swallow. In addition, clinician will be able to follow progression or regression of laryngopharyngeal sensitivity. As progress is made, a patient can then gradually begin to resume oral alimentation and the PEG can be removed with confidence.

\section{CONCLUSION}

This study demonstrates the applicability of a motor and sensory assessment of swallowing in a diverse group of patients with dysphagia. The purpose of FEESST is not as a screening tool nor to replace MBS. FEESST is suggested only for the evaluation of the patient with dysphagia. The hope is that FEESST will allow the clinician an additional series of objective measures to guide the behavioral and dietary management of their patients and reduce the risk of development of aspiration pneumonia.

\section{REFERENCES}

1. Alvarez S, Shell CG, Woolley TW, Berk SL, Smith JK: Nosocomial infections in long- 
term facilities. J Gerontol 1988; 43: M9-17.

2. Back-Sague C, Villarino E, Giuliano D, et al: Infectious diseases and death among nursing home residents: Results of surveillance in 13 nursing homes. Infect Control Hosp Epidemiol 1994; 15:494-496.

3. Garibaldi RA, Bondine S, Matsumiya S: Infections among patients in nursing homes. N Engl J Med 1981; 305:731-735.

4. Schmidt J, Holas M, Halvorson K, Reding M. Video-fluoroscopic evidence of aspiration predicts pneumonia but not dehydration following stroke. Dysphagia 1994; 9:7-11.

5. Martin BJW, Corlew MM, Wood H, Olson D, Golopol LA, Wingo M, Kirmani N. The association of swallowing dysfunction and aspiration pneumonia. Dysphagia 1994; 9:1-6. 6. Johnson ER, McKenzie SW, Sievers A. Aspiration pneumonia in stroke. Arch Phys Med Rehabil 1993; 74:973-976.

7. Holas MA, DePippo KL, Reding MJ. Aspiration and relative risk of medical complications following stroke.Arch Neurol 1994; 51:1051-1053.

8. Smithard DG, O'Neill PA, Park C, Morris J, Wyatt R, England R, Martin DF. Complications and outcome after acute stroke. Does dysphagia matter? Stroke 1996; $27: 1200-1204$.

9. Splaingard M, Hutchins B, Sulton L, Chaudhuri G: Aspiration in rehabilitation patients: videofluoroscopy vs. bedside clinical assessment. Arch Phys Med Rehabil 1988; 69:637-640. 10. Barer $\mathrm{DH}$. The natural history and functional consequences of dysphagia after hemispheric stroke. J Neurol Neurosurg Psych 1989; 52:236-241.

11. DePaso W. Aspiration pneumonia. Clin Chest Med 1991; 12:269-284.

12. Langmore SE, Schatz K, Olsen N. Fiberoptic endoscopic examination of swallowing safety: a new procedure. Dysphagia 1988; 2:216-219.

13. Langmore SE, Schatz K, Olsen N. Endoscopic and videofluoroscopic evaluations of swallowing and aspiration. Ann Otol Rhinol Laryngol 1991; 100:678-681. 
14. Ekberg O, Nylander G. Cineradiography of the pharyngeal stage of deglutition in 250 patients with dysphagia.Br J Radiol 1982;55:258-262 .

15. Logemann JE. Evaluation and treatment of swallowing disorders. College Hill Press, San Diego. 1983, pp. 214-227.

16. Murray J, Langmore SE, Ginsberg S, Dostie A. The significance of accumulated oropharyngeal secretions and swallowing frequency in predicting aspiration. Dysphagia $1996 ; 11: 99-103$.

17. Crary MA, Baron J. Endoscopic and fluoroscopic evaluations of swallowing:comparison of observed and inferred findings. Dysphagia 1997; 12:108.

18. Aviv JE, Martin JH, Sacco RL, Zagar D, Keen MS, Blitzer A. Supraglottic and pharyngeal sensory abnormalities in stroke patients with dysphagia. Ann Otol Rhinol Laryngol 1996; 105: 92-97.

19. Aviv JE, Sacco RL, Thomson J, Tandon R, Diamond B, Martin JH, Close LG. Silent laryngopharyngeal sensory deficits after stroke. Ann Otol Rhinol Laryngol. 1997; 106: 8793.

20. Kidd D, Lawson J, Macmahon J. Aspiration in acute stroke: a clinical study with videofluoroscopy. Quart J Med 1993; 86: 825-829.

21. Horner J, Massey EW, Riski JE, Lathrop DL, Chase KN. Aspiration following stroke: clinical correlates and outcome. Neurology 1988; 38: 1359-1362.

22. Horner J, Massey EW. Silent aspiration following stroke. Neurology 1988; 38:317-319. 23. Aviv JE, Martin JH, Keen MS, Debell M, Blitzer A. Air pulse quantification of supraglottic and pharyngeal sensation: a new technique. Ann Otol Rhinol Laryngol 1993; $102: 777-780$.

24. Aviv, JE, Martin, JH, Jones, ME, Wee, TA, Diamond, B, Keen, MS, Blitzer, A: Age related changes in pharyngeal and supraglottic sensation. Ann Otol Rhinol Laryngol $1994 ; 103: 749-752$.

25. Wu Chih-Hsiu, Hsiao Tzu-Yu, Chen Jiann-Chyuan, Chang Yeun-Chung, Lee Shiann- 
Yann. Evaluation of swallowing safety with fiberoptic endoscope: comparison with videofluroscopic technique. Laryngoscope 1997; 107: 396-401.

26. Aviv JE, Kim T, Thomson JE, Sunshine S, Kaplan S, Close LG. Fiberoptic endoscopic evaluation of swallowing with sensory testing (FEESST) in healthy controls. Dysphagia $1997 ; 12: 110$.

27. Bastian RW: Videoendoscopic evaluation of patients with dysphagia: An adjunct to modified barium swallow. Otolaryngol Head Neck Surg 1991; 104: 339-350.

28. Aviv JE, Sacco RL, Mohr JP, Thompson JLP, Levin B, Sunshine S, Thomson JE, Close LG: Laryngopharyngeal sensory testing with modified barium swallow as predictors of aspiration pneumonia after stroke. Laryngoscope 1997.

29. Murakami, Y, Kirchner, JA: Mechanical and physiologic properties of reflex laryngeal closure. Ann Otol Rhinol Laryngol 81:59-71, 1972.

30. Boushey, HA: The response of laryngeal afferent fibers to mechanical and chemical stimuli. J Physiol 240: 153-175, 1974.

31. Korpas J, Tomori Z. Cough and other respiratory reflexes. In Herzog, H, ed. Progress in respiration research. Vol 12, Basel, Switzerland: S. Karger 1979: 251-263.

32. Wyke, B. Effects of anesthesia upon intrinsic laryngeal reflexes: an experimental study. J Laryngol Otol 82: 603-612, 1968.

33. Mohr JP. Vertebrobasilar occlusive disease. In: Barnett HJM, Mohr JP, Stein BM, Yatsu FM, eds. Stroke. 2nd ed. New York: Churchill-Livingstone; 1986: 475-496.

34. Cooper DM, Lawson W. Laryngeal Sensory Receptors. In Blitzer, A, Brin, MF, Sasaki, CT, Fahn, S, Harris, KS; eds. Neurologic Disorders of the Larynx. Thieme Medical Publishers, Inc. New York. 1992: 12-28.

35. Chusid, JG. The Cranial Nerves. In Chusid, JG, ed. Correlative Neuroanatomy and Functional Neurology. 17th edition. Lange, Los Altos, CA 1979: 103-106.

36. Groher ME. The detection of aspiration and videofluoroscopy. Dysphagia 1994; 9:147148. 
37. Crogan JE, Burke EM, Caplan S, Denman S: Pilot Study of 12-month outcomes of nursing home patients with aspiration on videofluorosocpy. Dysphagia 1994; 9:141-146. 38. Valenti WM, Trudell RG, Bentley DW. Factors predisposing to oropharyngeal colonization with gram negative bacilli in the aged. NEJM 1978; 298: 1108-1111. 39. Terpenning M, Bretz W, Lopatin D, Langmore S, Dominguez B, Loesche W. Bacterial colonization of saliva and plaque in the elderly. Clin Infect Dis 1993; 16(Supple. 4): S3 1416.

40. Langmore S, Terpenning M, Schork A, Chen Y, Murray JT, Lopatin D, Loesche WJ. Swallowing, functional and dental/oral status as predictors of pneumonia. Dysphagia 1997; $12: 110$

41. Norton B, Homer-Ward M, Donnelly MT, Long RG, Holmes GKT. A randomised prospective comparison of percutaneous endoscopic gastrostomy and nasogastric tube feeding after acute dysphagic stroke. BMJ 1996; 312: 13-16.

42. Hassett JM, Sunby C, Flint LM. No elimination of aspiration pneumonia in neurologically disabled patients with feeding gastrostomy. Surg Gynecol Obstet 1988; 167:383-388.

43. Olivares L, Segovia A, Revuelta R. Tube feeding and lethal aspiration in neurological patients: a review of 720 autopsy cases. Stroke $1974 ; 5: 654-657$.

44. Feinberg MJ, Knebl J, Tully J. Prandial aspiration and pneumonia in an elderly population followed over 3 years. Dysphagia 1996; 11:104-9 